\title{
A Discourse on Brazilian Popular Music and US Jazz Education
}

\author{
Almir Côrtes with Hafez Modirzadeh \\ State University of Campinas - UNICAMP \\ San Francisco State University \\ almircortes@iar.unicamp.br \\ fezmo@sfsu.edu
}

\begin{abstract}
During a 2013 post-doctoral grant funded by the São Paulo Research Foundation-FAPESP to conduct research on North American jazz education, Almir Côrtes spent several hours a week at his host institution, San Francisco State University, with Hafez Modirzadeh, Professor of Jazz and Creative Music Studies. Together, they discussed and compared improvisation pedagogies between their two institutions. The following is a summary of several months of discourse, with Modirzadeh's critical cross-cultural positions on jazz lending to Côrtes's own research on the teaching of musical improvisation in Brazil. Among points discussed are some of the parallels and problems of institutionalizing historical contexts of practice, and popular music in particular. What follows are their own interactive perspectives - referencing causes for the current state of teaching methods, proposing potentialities for future ones that lay ahead - always with the knowledge that through consistent dialogue, shared boundaries expand.
\end{abstract}

KEYWORDS: improvisation pedagogy, Brazilian popular music, jazz education, teaching methods, discourse

\section{Introduction}

Almir CÔRTES: Since the seventies, there has been significant growth in academic studies related to Brazilian popular music (Travassos 2005). ${ }^{1}$ Today, it is possible 
to find a fair amount of research with substantial transcription analysis that describes technical aspects of Brazilian styles such as choro, samba, baião, frevo, música caipira, and bossa nova, among others. As well, studies exist on musical procedures from composers, arrangers, and musicians that have played a major role in the development of Brazilian popular music throughout the twentieth century. But although such popular music has had a presence in academia for some time, the first official degree in this area was not offered until 1989, at the Art Institute of UNICAMP (State University of Campinas, São Paulo). Then, in 1998, a similar degree program was created at UNIRIO (Federal University of the State of Rio de Janeiro), and since that time, popular music degree programs have grown exponentially across Brazil, with most of these colleges still in the process of defining curricula for their programs. Following suit with jazz education in the United States, Brazilian popular music courses are becoming increasingly established in higher education, leaving musician-educators with the challenge of finding effective teaching methods that can cover the socio-historical elements of past musical periods within present curricular practices. As one colleague puts it: "Mostly, students in the academic situation are usually missing something and it is usually something from the past, something they can't get just by listening to the most current players" (Berkman 2013).

HAfEZ MODIRZADEH: Altogether, many jazz schools miss the original process of learning from the past that makes for personalized styles, honed from personal choices. This may be reintroduced to the classroom through a methodology of articulating the right kind of questions - where musicians reveal their larger purpose, as Dizzy Gillespie (1979: 490-493) points out from a modern jazz pointof-view:

I find nowadays that musicians are not as inquisitive as they used to be. You've got to want to know why. If you respect a guy's playing, and he does something and you don't know why, you say "Why did you do it?" What he does is easy to find; you can listen to the record. Why, is what is important. [...] The role of music goes hand-in-hand with social reformation - the changing of society to make things right because music is a form of worship. [...] Organic change means all the things we know have got to be changed around for the betterment of society as a whole. [...] Music must reflect society, world society, and the way the society is moving because musicians depend upon the society to sustain them; at the same time, music and musicians must help to set things right.

As early as 1950, Marshall Stearns - founder of the Institute of Jazz Studies at Rutgers - included in his NYU syllabus for one of the first jazz history courses in higher education, the view that "jazz is best examined within a worldwide, crosscultural, comparative context" (Walser 1999: 195). Worthy discussion remains as to why his introductory lecture statement did not become a model for future generations of teachers on the subject:

Lecture 1: Jazz Definitions. The musics of the world in general and the relationship of jazz to European (classical) music in particular. An exposition of the melodic elaboration of Hindu music, the formal elaboration of Balinese 
music, and the rhythmic elaboration of African music. The birth of the tempered scale and the exploitation of harmony by European composers. The case for jazz as a separate and distinct art-form to be judged by separate and distinct standards. (Stearns 1999: 196)

Currently, in regards to teaching jazz history, textbooks in the US are unfortunately formatted in an assembly-line manner, with chapters contrived chronologically, by decade, era and/or style, rather than according to the overlapping territories and circumstances musicians were raised in and worked under. Understanding regional dynamics over the course of the twentieth century would help in understanding why accompanying contextual features cannot be reproduced in an academic environment; students could then be encouraged to contextualize the music for their own time, place and purpose. History serves to inspire understanding of present and future expression in jazz, and popular traditions in general. The classroom danger is one of glorifying the codification of historical artifacts, rather than creating within its idiomatic parameters timely and relevant messages for the current generation of musicians. One reason is that the pedagogical perpetuations of repertoire are continually shaped according to European classical models - this goes for any institutionalized music that follows conservatory standards.

\section{Thoughts on music industry and academia}

Almir CÔRTES: Certainly, from 1920 to 1950 there was a time of professionalization for the musicians in Brazil. This period encompasses the golden era of radio, and the boom of the record industry. Radio stations began appearing around the twenties in Brazil, and broadcast of live and recorded musical performances became a major product for the radio and record industry (Napolitano 2007). This brought about a new need to classify various types of music; hence, the nomenclature of Brazilian genres was born. Although most of these genres existed previously, they were first stylized and classified during this period. However, it is important to say that the "rules" defining the different genres are not strict. Indeed, they are in constant transformation. During this period, the "school" of many musicians was the act of playing on live radio shows, recording with bands and singers, and making their own records. Therefore, the golden radio era in urban areas everywhere had an impact on the modern development of traditional music. Brazilian music and US jazz reflect worldwide directions and changes that have been happening since at least the advent of a middle class during the nineteenth century, with the industrial revolution, ${ }^{2}$ and the subsequent development of technology that gave birth to the phonograph, on through World War II, with the golden age of radio. All of these events led to a rapid dissemination of music all over the world. By the twentieth century, as urbanization increased, regional styles gravitated to the city, becoming more standardized, with performers even more celebrated for their individual styles. 
Hafez MODIRZADEH: Agreed, urbanization was a worldwide phenomenon throughout the twentieth century, where a variety of music from rural areas interacted in cities, and with this, elements of modernization are said to have overlapped with Westernization, involving "attempts to make indigenous musical systems compatible with a Western-derived economic and social mode of living and to make the indigenous system musically competitive while retaining its integrity" (Nettl 1978: 168). Ethnomusicologist Bruno Nettl continues with a theory on tradition and change, based on his Persian musical research, considered here as well:

We may view a musical system as consisting of a core [idiom, repertory] and a surrounding superstructure [performance venue, instruments, musical roles]. The role of the superstructure is somehow to maintain the core intact, at the expense of changing itself $[\ldots]$ The superstructure has been flexible and adaptable [using ideas of westernization and techniques of modernization], while the core has remained relatively stable [but occasionally giving way to syncretistic tendencies] [...] Had the core changed greatly, one could perhaps speak of the death of a tradition. (ibid.: 179-180)

So possibly, from codifying the formulaic, or dogmatizing concert music in fixed rather than fluid ways, tradition carries on with a conservatory approach functioning as the changing superstructure that preserves its core language and material. Now, as twenty-first century musicians and educators, in the wake of an electronic revolution, shouldn't we expect this superstructure to change yet again, or more poignantly, to experience cores of traditions diffused into cultural compost for growing something else?

In my opinion, an overall commodification process particular to the US has affected musical academies just as it has historically affected ethnic and other culture-based communities. ${ }^{3}$ A competition dynamic with the goal to create a marketable product of sound brings with it ambitions that, in turn, may become abusive towards musicians and aspiring students alike. It seems to me, then, that the integrity of current educational environments suffers at the hiring of at least three kinds of predominantly misguided teachers: 1) the "cleric", who indoctrinates students with the perspective that only one path exists to play the music "correctly", who sees everything in a static chronological order; 2) the "recruit", who enjoys an "us vs them" kind of competition, scrapping any trace of individuality and focusing, rather, on the program; and 3) the "con-artist", who does not enjoy teaching, but does it for the use of facilities, or other profit-seeking motives (Modirzadeh 2004).

AlMIR CÔRTES: Overall, musicians and educators tend to agree that market values are not all the same, for the market itself has changed quite a lot. Regarding technique and virtuosity, levels seem to be going higher and higher, while the number of venues and audience is going lower and lower. There is also the issue of originality versus degree-driven "cookie-cutter" programs I think there should be caution not to reproduce market tendencies or build a new market inside colleges. Academia should be the place that allows musicians to have autonomy, 
so they can instead reflect and question values that have been imposed by/for the market.

HAfEZ MODIRZADEH: In 1995, the following study was published, on jazz market audiences:

The overall profile reveals an audience base that is affluent, well educated, youthful, and ethnically diverse [...] Participation in jazz correlates strongly with education and income. Nearly half of those attending jazz performances, for example, are college graduates, over three-quarters have had some college education. Those earning more than $\$ 50,000$ a year are more than twice as likely to attend performances as those earning less than $\$ 25,000$ [...] The audiences for jazz and classical music overlap to a considerable extent: roughly a third of those who attend performances of one genre also attend performances of the other. (DeVeaux 1999: 391-392)

\section{Interactive perspectives on teaching popular music}

HAfEz MODIRZADEH: Classrooms have their own experiential context, different, of course, from that which was the norm during the early-mid twentieth century both in the US and Brazil. Although these past experiences cannot be recaptured, educators can syncretize past with present, both in personal and collective storytelling ways. I conduct a form of "automythology" with students, to integrate their own stories within the larger musical legends they are familiarized with, in order to validate their own experiences with the ones that need to be more humanized than idolized. Realizing that it is healthy to recombine elements of hip hop, bluegrass, or any other genres with one's own, is to accept that inherent in tradition is change. This revolves around the main issue that within the world of music, there has never been a need to learn about the past in a chronological way. One does not need to know earlier styles in order to learn something more recent. Technological advances have students today familiarizing themselves with past and current styles simultaneously, breaking with linear chronological approaches altogether. This learning process - particularly in the aural way in which jazz improvisation unfolds - is the nature of the music itself (Modirzadeh 2004).

AlMIR CÔRTES: Indeed, it is better to deconstruct the idea that early jazz or samba is more "primitive" than bebop or bossa nova. It is wrong to think about, for instance, all the harmonic and melodic tools used currently as an evolution, or an improvement of earlier forms. In order to develop a coherent methodology for teaching improvisation in popular music in colleges, it seems to be necessary to find a balance between activities that are part of non-academic music training procedures based on jazz theory as well as techniques developed for western classical music. They are indeed the same in focus on repertoire and idiomatic study. Some Brazilian genres (for example choro) have more emphasis on repertoire; for the more jazz-inspired, it is improvisation that has, as the common 
goal in jazz programs, a value system of being articulated inside the language (or idiom).

HAfEz MODIRZADEH: And to help develop a more native approach altogether, research study in jazz can be used to develop effective cross-cultural methodology in improvisation (the life-blood of a living tradition); this involves "how" exactly "what" is analyzed. Jost (2004: 89-96) refers to "micro" versus "macro" structures in jazz improvisation of the sixties, an era still underrepresented in curricular material:

In the collective improvisations of [Ornette Coleman's] Free Jazz, the contributions of each and every improviser have a certain melodic life of their own; motivic connections and dove-tailing of the various parts create a polyphonic web of interactions. In [John Coltrane's] Ascension, on the other hand, the parts contribute above all to the formation of changing soundstructures, in which the individual usually has only a secondary importance. Quite plainly, the central idea is not to produce a network of interwoven independent melodic lines, but dense sound complexes. [...I]n Ascension, the macro-structures of the total sound are more important than the microstructures of the parts. [...T] he chamber-music dialogue between musicians, which was Coleman's principal aim, is succeeded by orchestral sound structures. No longer does the whole take its meaning from the constituent elements. Just the reverse: the elements now cannot be understood except by reference to the whole.

This may be related to a Brazilian educational context as well, to understand its own music. The fact that Jost is discussing jazz of the sixties - which breaks with previous modern jazz harmonic forms - suggests a focus here beyond the aspect of teaching jazz theory as conventional harmonic progression. With Coleman and Coltrane of the mid sixties, the modalities shift us towards the study of oral tradition within a different perspective - one offering alternatives to the formal structures of what can be called the colonial continuum (where academic culture continues to apply a value system founded on eighteenth-nineteenth century Western European harmony).

In a sense, the communal way in which Hermeto Pascoal transmits his music may be considered counter-colonial, or better, as an alternative institutional structure much like that of Duke Ellington, Sun Ra, or other jazz masters' ensembles that have served as breeding grounds for advancing the music. These mentors allowed for personal autonomy in their groups, promoting individuality for the sake of a collective growth, similar to the socio-musical structure of their African heritage. So, such contexts that may seem subversive for a classroom setting can be converted instead into concepts that otherwise serve the same purpose. As all such consummate artists transcend mainstream forms, a-linear or multidimensional musical culture is subversive in its cohesiveness. To separate the parts is to extinguish the whole - where meaning cannot be derived out of context, it is antithetical to the analytics that are commonly used in institutional environments. 
AlMIR CÔRTES: Certainly most of the tools and strategies developed and used in academic settings were not part of the musical training for those musicians that were working during the early to mid-twentieth century in Brazil. There are a good number of non-academically trained musicians with expertise in styles such as choro, tango (as well as jazz), who have learned mainly by playing and memorizing a large number of songs. Instead of dividing music into small units and analyzing these to come up with patterns (most of the time using techniques developed in western classical music), these experts gained their musical knowledge differently: acquired through a lifetime of performance practice of an enormous repertoire. For instrumentalists, their fingers get accustomed to certain positions and their ears and memories recognize musical elements that many songs have in common. Those elements become part of their vocabulary, and they "speak" in this "idiom" when they improvise.

At the same time, we cannot say that non-formal musical training is based exclusively on imitation, and is ideal without technical support. There are examples of some great instrumentalists that have succeeded in this way, but many others who tried were not able to achieve such good results. Indeed, the length of time necessary to become proficient without formal training should be taken into account. The act of learning based only on a process of trial and error, without any kind of systematization, requires a great deal of time - it is indeed a time-consuming task, for example, to solve technical problems, or even theoretical questions, by means of experimentation. Therefore, it is important to carefully weigh the pros and cons of formal versus fluid musical practices.

HAfEZ MODIRZADEH: The development of a musician through culture takes time, and, contrary to "formal" education, integrates all the elements of that culture into his/her music, including dance, language, food, and so on. Therefore, as culture develops within a contained environment over time, so the jazz language was raised within African American communities during years of segregation in the US. But with formal institutionalization has come a lack of connection with a musical peoples' history (socio-economic and otherwise), and, instead, the focus remains fixed on the sound-structures that resulted therefrom. Consequently, cultural context is dimmed to the point of extinguishment, leaving the technical side of virtuosity and the concert music context to sustain these structures within conservative formats. Today though, methodology can more readily adapt alternative approaches with broadly applicable concepts. Some of these concepts, as ideas, can be derived from the sciences and so have interdisciplinary application. For example, the concepts of periodicity and pulsivity [Modirzadeh's term] (or fixed recurrences in contrast to flexible ones), as well as re-assemblage patterns in large and small improvisation contexts, may work well in the classroom. In fact, there are numerous ethnomusicological studies that apply the latter perspective across a variety of cultures (Nettl 1998). Some thirty-forty years ago, the mission for the academy was to recognize jazz as an exclusive art form worthy of the same scholarly recognition as western European music, and this has come to pass, and with this, some of the same elitist attitudes have surfaced as side-effects as well, unfortunately. 
ALMIR CÔRTES: Beginning in the seventies, the methodology developed in the US to teach jazz improvisation started to become known in Brazil and many Brazilian musicians used that kind of material during their training (methods by George Russell, Jerry Coker, and David Baker, to name a few). Consequently, that methodology has become one of the main pedagogical tools to teach improvisation in Brazilian popular genres, in private lessons, and other educational contexts (Côrtes 2012). Based on interviews with teachers and musicians experienced in this area, it appears that jazz theory has been used to teach Brazilian music in an empirical way: it happened without much reflection on the possible implications that the usage of jazz theory could generate for the teaching of improvisation in Brazilian music. It is worth mentioning that, often times, the study of improvisation in Brazil has been confused with the teaching of musical elements representative of a variety of specific jazz languages (bebop being the most common example). Therefore, it seems that the search for a specific methodology to teach Brazilian styles is one of the current challenges in Brazilian music education (especially for pre-bossa nova styles). ${ }^{4}$ This does not infer that the contributions of jazz education are to be ignored, but rather they should be looked upon critically, seeking a healthy integration of jazz theoretical elements that can function in an indigenously Brazilian sort of way. It is important to understand what has already been done in this area in order to adapt some jazz tools and strategies, while also bearing in mind that possibly only a select few of these tools could work appropriately in Brazilian musical education contexts:

\begin{abstract}
Classifying pre-institutional learning strategies as an oral phenomenon provides an epistemological excuse for positioning the advent of institutionalized instruction as a significant event in the history of music education. The failure of the institutional narrative to demonstrate a relationship between such events and performance practices of jazz leaves us with only a partial understanding of why jazz education came about and was able to function as it did. What is missing from the history of jazz education is an understanding of how musician/educators were able to adapt the methods and musical materials of jazz into a form that could successfully be employed within the academic context. This involves an examination of the development of "jazz theory". (Prouty 2005: 92)
\end{abstract}

HAfEz MODIRZADEH: Jazz education can easily become a practice of theory mostly, a theory of harmony - although rhythm is really the essential aspect. Therefore, the study of jazz practice is incomplete without involving some dance, as well as song and bandstand protocol, all of which are again, part of many cultures' original context, and also of the aforementioned "free" jazz of the sixties, which in itself does present pre-modern elements - this is why its curricular implementation may benefit the study/practice of pre-bossa nova styles as well.

But as jazz education spread more formally since that time, it is true that it has been propelled by harmonic innovation of the twentieth century, both from European classical and American jazz traditions. This sounds like the primary impetus for Brazilian musical education as well - a methodology steeped in harmonic advancement - while rhythmic sensibility remained pedagogically more elusive, relying on the cultural experiential, much as with jazz also. After all, the theory of pitch systems can be transmitted more readily in published book form 
than rhythmic sensibility. No matter how many accented measures are on the page, the rhythmic aspect of the idiom is taught through contextual experience more so than in theoretical formats. And where curriculum is based on a paradigm of European classical music, rhythmic training for non-percussionists can be merely secondary, or simply implied in the lesson material. Dizzy Gillespie (1979: 431-432) has pointed out, though, that in the case of South America, and Brazil in particular, rhythm has remained an integral part of musical conception: "Our music has influenced Brazilian music harmonically [...a]nd they influenced our playing, rhythmically. All this music had the same mother; the main source of inspiration is the rhythm. That makes it different from European classical music".

\section{Music programs with integrated theory and practice}

ALMIR CÔRTES: Taking into account all the points discussed above, it seems that music programs should prioritize starting with performance first, before moving on to applied theory. While working towards building a reflexive musical practice, ideas and thoughts should be derived from questions that arise during practice sessions. For instance, as a background to the study of improvisation, it is possible to use a specific groove with a set of chord progressions that are recurrent in the repertoire of a chosen style. On top of that, idiomatic lines could be conceived first by ear, and once played accurately, students can move on to transcriptions and theoretical analysis. This order makes it easier to introduce musical concepts to students, informing them about possible paths to take later with the musical elements they are learning. Once students get a grip on the musical aspects, it will be much more stimulating to have a discussion on when and how Brazilian popular music or jazz styles were shaped, what the sociohistorical context was like, and the role radio, artists, journalists, critics, and the government, played in this process. A reflexive musical practice can also pave the way for healthy debate on some of the thoughts and attitudes surrounding the idea of "traditional" music in general. The teacher could put it in perspective by performing together with students selected pieces that illustrate compositions that represent "traditional styles", alongside compositions that are related to that "tradition", while still pushing boundaries with some experimentation. These topics are strictly related with the notion of musical language and "idiomatic improvisation" (Bailey 1993).

At the same time, while building a stronger interest in performance, it is possible to motivate involvement with other cultural practices that relate to the shaping of popular music styles with such components as dance and song. Brazilian popular music and jazz education could benefit from this kind of approach, continuing their inherently syncretic ways by integrating applied theory with performance practice and expanding this with interdisciplinary study across other areas as well.

HAfEZ MODIRZADEH: In practice, beyond area focus, a well-developed music program could integrate instrumental forms with vocal and percussion forms, and movement or dance. Throughout Brazilian socio-cultural history, such 
interdependence has existed in both traditional and popular musical forms; however, as with the US and other countries, this interdependence has gone largely unnoticed by formal music educators. Music students, for the sake of area specialization, are generally not required to experience interlocking practices that would have an instrumentalist dancing, a dancer drumming, and both, singing. Jazz subjects, as with other popular music programs, get compartmentalized to the point of denying students a semblance of the original processes that generated this music in the first place - which would also include spoken word - processes that involve deliberate variation on models (also referred to as "idiomatic improvisation"). In particular, West African tonal and rhythmic sensibilities have informed the popular music of both Brazil and the US, and therefore, should be required in their indigenous American forms by all programs. Of course, such required curricula would be accompanied by the hiring of instructors highly regarded as masters in the respective communities from which such practices have emanated. As well (and ideally), along with Western European ("classical") musical forms, selected West to East Asian musical understanding would help complement practices from the African diaspora, bringing about tonal and temporal innovation of an even more personalized nature. For instance, any/all curricula that can require Western musicianship alongside Indonesian gamelan and West African drumming have the potential to empower students tremendously.

Interlocking the learning of such practices applies to music theory as well, both in historical and philosophical terms. Investigation of musical systems that inform beyond the Western classical canon would allow for more original creations based on specific cultural abstractions. This however, would require a whole new generation of instructors able to define, relate, and nurture personal experiments derived from such concepts as Hindustani raga, Persian dastgah, Arabic maqam, or any variety of jazz approaches. An understanding that is expansive, moving between the particular and universal, discerning between inclusive and exclusive perspectives, strengthens rather than blurs traditional focuses. Theoretical studies, though, would not be possible in this case without concurrent relating of the historical elements involved, which may cover a wide-range of selected extramusical systems - social, political, religious, etc. - as well as any of the arts or sciences conceived in their own contextual periods. And finally, to cap-off a wellrounded curriculum, at least two more courses can be offered: 1) to cover the range of music technology available at that time, including instrument-building, and 2) to cover the range of directions possible for the music graduate, both privately and professionally.

Once again, such action requires innovative instructional practices to encourage concrete change in our academic culture. With this, specialization within graduate or performance degree levels can be strengthened by wellcoordinated undergraduate programs geared towards creative-spirited rather than conservatory-minded musicianship. The latter though, without the former, results in musicians (and composers and teachers) perpetuating their own disempowerment, as economic ambition (or job-to-job desperation) then plays into the societal imbalances that result in discrimination, classism, and elitism. As such, reward-conflicts between "popular" and "classical" musical prowess are regulated and institutionalized, both publically and privately. But certainly, any 
curriculum structured to genuinely nurture the kind of original thought that could effect positive change in the individual and society, would most likely consider such issues and resolutions in a complementary rather than competitive light.

\section{Final considerations}

AlmiR CÔRTES: Interviews and observations conducted at CalArts in 2013 (California Institute of the Arts, Los Angeles, California) - specifically with David Roitstein (jazz program director at CalArts) and guitarist Tim Fischer (doctoral candidate at USC and Master's degree holder from CalArts) - demonstrate that the CalArts jazz program is making progress towards this balance I initially spoke of, between outside/inside institutional contexts: students, besides receiving formal training, have many opportunities to gain more practical experience via concert performances, recording sessions, and project collaborations.

HAFEZ MODIRZADEH: Yes, the integration of both musical and extra-musical studies is key towards creating a more realistic training ground. Interdisciplinary cooperation in higher education, though, seems to me to be more of a political issue stemming from the competitive nature of academia, as departments and their faculty must effectively promote, fund, and staff, their own stand-alone program areas in order to survive.

Almir CÔRTES: Altogether, it is possible to question some paths found in jazz education: we come up with chord changes, scales, and jazz theory to derive tunes rather than the tunes and the improvisation thereof determining the theory. What then can keep Brazilian musical language from becoming museum music?

HAFEZ MODIRZADEH: This is the question - regarding the internalization process of such musical culture - although I think that as long as we are reflecting on a diversity of issues related to our music, a healthy theory precedes as well as succeeds any practice. Learning communities in all forms of traditional and creative music have repeatedly shown that a reflective nature

must occur within each musician who wants to honestly deal with all that encompasses this music for themselves: culturally, historically, socially, racially, sexually, politically, spiritually, whatever. In order to tell your own story, you must know who/where you come from and what you need to express. Then your action can match the intent for which you stand. (Modirzadeh 2004: 133)

So, in summary, here are some suggestions: 1) to find or make room for the experimental in academia, namely with regards to redefining curricula with training in more than one tradition; 2) to develop methods for students to relate their own stories to the larger historically collective one, thus creating seamless automythographies [Modirzadeh's term] between their present and a further past; 3) to adapt different transmission processes of various repertoire, thus instilling dynamic improvisation approaches; 4) to integrate specializations in order to 
create more original, holistic objectives; and 5) to explore older improvised musical processes of world cultures reflected in more recent practices (that is, premodern, pre-bossa nova styles with jazz liberations of the sixties and the creative music of today). Finally, contexts of past practices can be applied as concepts to keep the present fluid and relevant. As long as there are people, spirit will continue to shape form, and so, no music can ever actually die, for even when contexts change and structures adapt accordingly, music is itself not human, but only a reflection of the human experience.

Almir CÔRTES AND Hafez MODIRZADEH: Relevant methods of teaching sociohistorical elements of the past would benefit from positioning the musical culture of study within a larger, worldwide perspective, related to other peoples' music besides its own. For both written and oral traditions, bringing past together with a present experience over a world timeline is proving more in-step with today's information accessibility.

As Brazil today keeps modern jazz alive and well by integrating it into its own musical programs, Brazil also has the potential to model an education future that gives students as much creative opportunity to hone their own histories as that of their traditions. Dizzy describes the reason behind this potential the best:

Brazil really broadened my scope of what music is about. It showed the oneness of music and how music from different ethnic backgrounds can be merged in complete oneness, without each losing its distinctive qualities, without losing its diversity. It taught me unity with diversity in music. (Gillespie 1979: 430)

\section{Endnotes}

1 The term "Brazilian popular music" is not related to North American "pop music;" it makes reference to specific styles developed in Brazil during the twentieth century.

${ }^{2}$ For more details see Scott 2008.

3 Still, there are musical communities who have successfully defied the complete commodification of their cultural heritage. In Andalucia, Spain, for example, Gitanos continue to perform within their own exclusively private flamenco gatherings, keeping certain aspects of the tradition from being perpetually commercialized.

${ }^{4}$ For instance, during the fifties, the cultural "modernization" of Brazil was promoted both politically and artistically; radio audiences declined under the influence of television, shifting musical tastes. Therefore, bossa nova music, emerging in the late fifties, is now considered a watershed between "traditional" and "modern" music.

\section{Acknowledgements}

The authors would like to thank the São Paulo Research Foundation-FAPESP for funding this research via a Post-doctorate (BEPE-PD) fellowship, as well as San Francisco State University for serving as host institution. The content herein 
is solely the responsibility of the authors and does not necessarily represent the official views of FAPESP.

\section{References}

Bailey, D. 1993. Improvisation: Its Nature and Practice in Music. New York: Da Capo Press.

Berkman, D. 2013. Interview with David Berkman, jazz pianist and teacher at Queens College, by Almir Côrtes, 4 October.

Côrtes, A. 2012. Improvisando em música popular: Um estudo sobre o choro, o frevo e o baião e sua relação com a "música Instrumental" brasileira. PhD. Art Institute of UNICAMP, Campinas-São Paulo.

DeVeaux, S. 1999. Who Listens to Jazz. In R. Walser Ed. Keeping Time: Readings in Jazz History. New York: Oxford University Press: 389-395.

Gillespie, D. (with Fraser, A.) 1979. To Be or Not To Bop. New York: Da Capo Press.

Jost, E. 1994. Free Jazz. New York: Da Capo Press.

Modirzadeh, H. 2004. The Jazz Educators' Unholy Three. Cadence. September: 132-133.

Napolitano, M. 2007. A síncope das ideias: A questão da tradição na música popular brasileira. São Paulo: Fundação Perseu Abramo.

Nettl, B. 1978. Persian Classical Music in Tehran: Processes of Change. In Eight Urban Musical Cultures. Urbana: University of Illinois: 146-185.

Nettl, B. and Russell, M. Eds. 1998. In The Course of Performance: Studies in the World of Musical Improvisation. Chicago: University of Chicago Press.

Prouty, K. E. 2005. The History of Jazz Education: A Critical Reassessment. Journal of Historical Research in Music Education 26 (2): 79-100.

Scott, D.B. 2008. Sounds of Metropolis: The 19th-Century Popular Music Revolution in London, New York, Paris and Vienna. New York: Oxford University Press.

Stearns, M. W. 1999. Jazz in the Classroom. In R. Walser Ed. Keeping Time: Readings in Jazz History. New York: Oxford University Press: 195-199.

Travassos, E. 2005. Pontos de escuta da música popular no Brasil. In M. Ulhôa and A.M. Ochoa Eds. Música popular na América Latina: Pontos de escuta. Porto Alegre: Editora da UFRGS: 94-111. 